\title{
Beta-3 agonist-induced lipolysis and nitric oxide production: relationship to PPARgamma agonist/antagonist and AMP kinase modulation
}

\author{
Jiří Hodis ${ }^{1}$, Radka Vaclavíková ${ }^{2}$ and Hassan Farghali ${ }^{1}$ \\ ${ }^{1}$ Institute of Pharmacology, First Faculty of Medicine, Charles University, Prague, Czech Republic \\ 2 Biotransformations Group, National Institute of Public Health, Center of Occupational Diseases, Prague, Czech Republic
}

\begin{abstract}
PPARgamma receptor agonist - troglitazone increases insulin sensitivity in visceral adipocytes and also increases fat mass. Beta-3 adrenergic receptor agonists mediate lipolysis and NO production (iNOS transcription) in visceral adipocytes. Troglitazone could possibly interfere with Beta-3-triggered lipolysis. We tested the crosstalk between PPARgamma agonist and Beta-3 agonist pathways on lipolysis and $\mathrm{NO}$ production in first 24 hours of treatment. Isolated epididymal rat adipocytes were cultivated in DMEM for 24 hours with treatment with Beta-3 agonist - BRL-37344, PPARgamma agonist - troglitazone, PPARgamma antagonist - SR-202 and AMPK blocker - compound $\mathrm{C}$ alone as well as in combinations. After 24 hours, lipolysis was measured by free glycerol, NO production by Griess reagent and iNOS mRNA by qRT-PCR. BRL-37344 increased lipolysis and NO production with iNOS transcription. Troglitazone increased all the three parameters as well but less than BRL-37344. Combination of troglitazone or SR-202 with BRL-37344 decreased NO production, iNOS transcription and lipolysis triggered before adding of BRL-37344. Compound C completely blocked the effect of troglitazone (and SR-202 as well) on BRL-37344. PPARgamma agonist/antagonist interferes with Beta-3 agonist activity in 24 hours. Troglitazone/SR-202 effect on Beta-3 triggered lipolysis and iNOS mRNA production is probably not PPAR gamma- but rather AMPK-dependent in first 24 hours (AMPK blocker - compound C blocked the effect).
\end{abstract}

Key words: Nitric oxide - Lipolysis - Adipocytes - Beta-3 agonists - Troglitazone - PPARgamma

\begin{abstract}
Abbreviations: AMPK, adenosine monophosphate kinase; ANP, atrial natriuretic peptide; HSL, hormone sensitive lipase; MAPK, mitogen activated protein kinase; MGL, monoglyceride lipase; NEFA, non-esterified fatty acids; NFkB, nuclear factor kB; NOS, NO synthase; nNOS neuronal NOS; eNOS, endothelial NOS; iNOS, inducible NOS; PKA, protein kinase A; PKC, protein kinase C; PKG, protein kinase G; PPARgamma, peroxisome proliferator-activated receptor-gamma.
\end{abstract}

\section{Introduction}

Peroxisome proliferator-activated receptor-gamma (PPARgamma) agonists (glitazones, thiazolidindiones) along with metformin are known as anti-insulin resistance drugs and are approved by EASD (European association for the Study

Correspondence to: Jiří Hodis, Institute of Pharmacology, First Faculty of Medicine, Charles University, Albertov 4, 12000 Prague 2, Czech Republic

E-mail: hodis@atlas.cz of Diabetes) and ADA (American Diabetes Association) for diabetes mellitus type 2 treatments (Nathan et al. 2009). Beside PPARgamma specific activity glitazones were described to have nonPPAR gamma - AMPK direct activating effect (LeBrasseur et al. 2006). PPARgamma specific antagonists were developed, from which SR-202 (phosphonophosphate) was reported to modulate selectively PPARgamma transcriptional activity both in vitro and in vivo (Rieusset et al. 2002). Beside glucose-lowering effect, glitazones led to weight gain, increased fat mass partially by improving the adipocyte's insulin sensitivity. The increase of the fat mass 
after PPARgamma agonists is dependent on induction of lipogenic enzymes acyl-coenzyme A (acyl-CoA): diacylglycerol transferase and fatty acid synthetase together with marked decrease of non-esterified fatty acids and triacylglyceride levels in blood (Schoonjans et al. 1996), lipoprotein lipase enhancing subsequent entrance of non-esterified fatty acids into adipocyte from vessel (Ranganathan et al. 2006) or intracellular transport facilitating proteins - fatty acid transport protein and acyl-CoA synthetase (Martin et al. 1997). The inhibition of lipolysis may be the other possible explanation.

Lipolysis in adipocytes is performed mainly by 3 known lipases: hormone sensitive lipase (HSL), adipose triglyceride lipase (ATGL) and monoglycerol lipase (MGL) (Arner 2005). HSL is activated mainly by phosphorylation performed by two proteinkinases: PKA triggered by cAMP and PKG triggered by cGMP. cGMP increase is the result of atrial natriuretic peptide (ANP) or NO stimulation (Lafontan et al. 2006). One mode of increase HSL activity via phosphorylation is dependent on NO (cGMP) site1 phosphorylation by PKG (Garton et al. 1989). That is why NO should be involved in concerting HSL lipolysis.

$\mathrm{NO}$ as a free radical gas is generated by $\mathrm{NO}$ synthase (NOS; EC 1.14.13.39) in living organisms. The family of NOS enzymes consists of two constitutive isoforms, neuronal NOS (nNOS, NOS-I), endothelial NOS (eNOS, NOS-III), and one inducible NOS (iNOS, NOS-II) (Knowles and Moncada 1994; Alderton et al. 2001). In fat tissue iNOS plays the main role in NO production while eNOS production of NO production is low and nNOS has not been detected in adipocytes (Elizalde et al. 2000). NO production in adipocytes is mainly triggered by iNOS mRNA transcription. This mechanism is reviewed in some reports (Fryer et al. 2000; Jobgen et al. 2006). iNOS transcription and/or activation can be increased by Beta- 3 agonists with cAMP as second messenger and PKA consequently (De Groot et al. 2003; Dessy et al. 2004; Canova et al. 2006). It was reported that CCAAT box (C/EBP binding site, positions $-155 \mathrm{bp}$ to $-163 \mathrm{bp}$ ) is essential for cAMP-mediated induction of the rat iNOS promoter with involvement of C/EBPbeta and C/EBPdelta (Eberhardt et al. 1998). This mechanism is supposed in BRL-37344 triggered iNOS mRNA transcription as this pathway is unique for BRL-34344 treatment without concomitant side (ERK/MAPK) pathways (Gerhardt et al. 1999). NO as the main molecule of vasodilatation is being recognized to have metabolic consequences with impact on different metabolic pathways as reviewed earlier (Kleinert et al. 2003, 2004).

According to available literature, the short-term interaction of PPARgamma agonist or PPARgamma antagonist with Beta-3 agonist in primary isolated epididymal rat adipocytes has not been reported so far.

The present work, therefore, was directed to shed light on the crosstalk between Beta- 3 mediated lipolysis and
NO production and the consequences of the PPARgamma agonist co-treatment. The selection of Beta-3 agonist as pharmacological tool is justified in the present work to help to differentiate the PPAR gamma agonist and antagonist effect on stimulated lipolysis and NO production.

Clarifying of the interactions mentioned above can help and lead to further step towards understanding adverse effects of glitazones in fat tissue and contribute to future investigations in seeking effective anti insulin-resistance drugs and antiobesity drugs.

\section{Materials and Methods}

\section{Experimental animals}

Male Wistar rats (Velaz-Lysolaje 250-350 g body weight, age 1.5-2 month) were used throughout the presented studies. Rats obtained tap water and standard granulated chow ad libitum and were maintained under standard $12 / 12 \mathrm{~h}$ light/dark cycle, temperature $22 \pm 2{ }^{\circ} \mathrm{C}$ and relative humidity $50 \pm 10 \%$. All rats were cared in compliance with the general guidelines of the First Faculty of Medicine, Charles University in Prague. The study protocol was approved by the Faculty Ethical Committee.

\section{Isolation of rat white adipocytes}

The rats were sacrificed and the epididymal fat pads were removed and kept in saline at $37^{\circ} \mathrm{C}$. After drying in a piece of gauze, dissected fat pads were cut into small pieces and processed to the adipocyte isolation by collagenase digestion as described earlier (Rodbell 1964).

Briefly, adipose tissue was digested in a plastic vial with Krebs-Ringer bicarbonate buffer (KRB; in mM: $121.0 \mathrm{NaCl}$, $5.95 \mathrm{KCl}, 14.3 \mathrm{NaHCO}_{3}, 1.34 \mathrm{NaH}_{2} \mathrm{PO}_{4}, 1.2 \mathrm{MgCl}, 8 \mathrm{~L}-$ glutamine, $2.5 \mathrm{CaCl}_{2}$ and 12.7 glukose; $\left.\mathrm{pH} 7.4\right)$ containing $2 \%$ bovine serum albumin (BSA) and $2 \mathrm{mg}$ collagenase $/ 5 \mathrm{ml}$ of solution for $2 \mathrm{~g}$ of adipose tissue. The adipose tissue was subjected to constant shaking at $37^{\circ} \mathrm{C}$ for $60 \mathrm{~min}$. After this incubation period, fat cells were separated from connective tissue by filtration through a nylon mesh $150 \mu \mathrm{m}$. The isolated adipocytes were washed three times with glucose-free KRB (in mM: $136 \mathrm{NaCl}, 4.7 \mathrm{KCl}, 1.25 \mathrm{MgSO}_{4}, 1.25 \mathrm{CaCl}_{2}$, $5 \mathrm{Na}_{3} \mathrm{PO}_{4}, 2 \mathrm{NaHCO}_{3}, 25 \mathrm{HEPES}$ pH 7.4; with 2\% BSA) to remove collagenase and stromavascular cell fraction accumulating as an infranatant under the floating fat cells.

\section{Chemicals and reagents}

High-glucose Dulbecco's modified Eagle's medium (DMEM), penicillin-streptomycin solution $100 \times$ L-glutamine, BSA fraction V, fatty acid-free BSA, BRL-37344 sodium salt, tro- 
glitazone, SR-202, compound C (P-5499), DMSO, sulfanilic acid, $N$-(1-naphthyl)ethylene-diamine dihydrochloride and chromotropic acid were obtained from Sigma-Aldrich (Prague, Czech Republic).

Gibco fetal bovine serum (FBS) was purchased from KRD (Prague, Czech Republic) and the crude collagenase was obtained from Sevapharma (Prague, Czech Republic). All other chemicals were obtained from standard sources and were the highest grade available or as described in Materials and Methods.

\section{Primary adipocyte culture and treatments}

Isolated adipocytes were incubated under sterile conditions in DMEM medium, $\mathrm{pH} 7.4$, supplemented with $2 \mathrm{mM} \mathrm{L-}$ glutamine, $10 \% \mathrm{FBS}, 100 \mu \mathrm{g} / \mathrm{ml}$, streptomycin and $100 \mathrm{IU} / \mathrm{ml}$ penicillin. BRL-37344, SR-202 or troglitazone was added before fat cells seeding directly to the culture medium to obtain the final concentration of $0.2 \mu \mathrm{M}$ BRL-37344 (published non toxic concentration up to $10 \mu \mathrm{M}$, Gerhardt et al. 1999), 130 $\mu \mathrm{M} \mathrm{SR}-202$ (published non toxic concentration up to $400 \mu \mathrm{M}$, Rieusset et al. 2002), $40 \mu \mathrm{M}$ troglitazone (minimal effect on mRNA iNOS seen above $10 \mu \mathrm{M}$, Pilon et al. 2004; minimal effect in decrease of inflammatory cytokines above $30 \mu \mathrm{M}$ and no cytotoxic effect was seen till $60 \mu \mathrm{M}$ troglitazone in some studies, Ji et al. 2001).

$500 \mu \mathrm{l}$ of packed adipocytes were placed in the $5.5 \mathrm{ml}$ of enriched DMEM in air tight sterile polystyrene Petri dishes (Merci, Prague, Czech Republic) and maintained at $37^{\circ} \mathrm{C}, 95 \%$ air, and $5 \% \mathrm{CO}_{2}$. The floating adipocytes formed a well-visible fat layer on the surface of the medium. Hence, the medium under the fat cells was considered an infranatant. The dish-wares were loosely covered by lids and gently shaken. The treated and untreated adipocytes were incubated for $24 \mathrm{~h}$ as described in Table 1 which demonstrates the treatment schedule with relevant Figures shown in results section.

\section{Determination of NO production}

NO production was determined by measuring the levels of its oxidation end products $\mathrm{NO}_{2}{ }^{-}$and $\mathrm{NO}_{3}{ }^{-}$. The data presented here were expressed as nitrite levels of the total amount of nitrite/nitrate after the conversion of nitrate to nitrite by nitrate reductase in the presence of reduced nicotinamide adenine dinucleotide phosphate. The nitrite formed was detected colorimetrically $(540 \mathrm{~nm})$ from centrifuged infranatant by nitrite/nitrate colorimetric method modified for 96-well plates or by Griess reagent ( $1 \%$ sulfanilamide, $0.1 \%$ naphthylethylendiamine, and $2.5 \%$ $\mathrm{H}_{3} \mathrm{PO}_{4}$ ). The nitrite levels were extrapolated from $\mathrm{NaNO}_{2}$ calibration curve.

\section{Determination of lipolysis}

Lipolysis was determined as the glycerol released to the culture medium from adipocytes. Glycerol medium levels were assessed spectrophotometrically $(570 \mathrm{~nm})$ according to a previously described method (Lambert and Neish 1950). Briefly, the $300-\mu l$ medium aliquots were rapidly transferred into glass tubes containing $300 \mu \mathrm{l}$ of $10 \%$ (w/v) trichloracetic acid. After shaking, the precipitates were separated by centrifugation at $3000 \mathrm{rpm}$ for $3 \mathrm{~min}$. Two hundred microliters of the supernatant was removed, mixed with $50 \mu$ of $0.05 \mathrm{M}$ $\mathrm{NaIO}_{4}$ and incubated for $10 \mathrm{~min}$ at room temperature. Then, $50 \mu \mathrm{l}$ of $2 \mathrm{M} \mathrm{As}_{2} \mathrm{O}_{3}$ dissolved in $10 \mathrm{~N} \mathrm{NaOH}$ was added. Ten minutes later, $2.5 \mathrm{ml}$ of chromotropic reagent, consisting of $30 \% \mathrm{H}_{2} \mathrm{SO}_{4}$ and water-dissolved chromotropic acid $(5.6 \mathrm{mM}$ end concentration in reagent), was added and the resulting mixture was boiled for $30 \mathrm{~min}$ in water bath. After cooling

Table 1. Treatments of Beta-agonist (BRL-37344), PPARgamma agonist (troglitazone), PPARgamma antagonist (SR-202) and AMPK blocker (compound C) and their combination (24 hours cultivation)

\begin{tabular}{|c|c|c|c|c|c|c|c|c|c|}
\hline \multirow{2}{*}{ Measured effect } & \multicolumn{8}{|c|}{ Treatment } & \multirow{2}{*}{ Fig. No. } \\
\hline & $\mathrm{B}$ & $\mathrm{T}$ & $S$ & $\mathrm{D}$ & $\mathrm{B}+\mathrm{T}$ & $\mathrm{T}+\mathrm{S}$ & $\mathrm{B}+\mathrm{T}+\mathrm{S}$ & $\mathrm{B}+\mathrm{T}+\mathrm{D}$ & \\
\hline $\begin{array}{l}\text { Lipolysis } \\
\text { (glycerol) }\end{array}$ & + & + & + & & + & + & + & & 1 \\
\hline $\begin{array}{l}\text { Lipolysis dependence on AMPK } \\
\text { (glycerol) }\end{array}$ & + & + & & + & + & & & + & 2 \\
\hline $\begin{array}{l}\text { NO production } \\
\text { (medium nitrite) }\end{array}$ & + & + & + & & + & + & + & & 3 \\
\hline $\begin{array}{l}\text { NO production dependence on AMPK } \\
\text { (medium nitrite) }\end{array}$ & + & + & & + & + & & & + & 4 \\
\hline $\begin{array}{l}\text { iNOS mRNA } \\
\text { (qRT-PCR) }\end{array}$ & + & + & & & + & & & & 5 \\
\hline
\end{tabular}

B, BRL-37344; T, troglitazone; S, SR-202; D, compound C. 
of the sample to room temperature, the absorbance of the purple product was measured colorimetrically at $570 \mathrm{~nm}$ and the glycerol levels were extrapolated from glycerol standard calibration curve.

The Beta-3-mediated lipolysis in adipocytes in 24 hours differs from that in the first 30 minutes. The period of 24 hours cultivation before measurement was suggested as compromise period between short acting catecholamines with maximal effect after 3 hours but still measurable activity in 24 hours and later on the activity of thiazolidinediones with ordinary time of action about 3 days. To minimize the possible downregulation of beta receptors after 3 days of cultivation as described earlier (Vicario et al. 1998), BRL37344 as Beta-3 selective agonist was chosen among others because Beta- 3 receptor is described to be the least down regulated beta receptor (Carpene et al. 1993; Nantel et al. 1993) with stable BRL-37344 activity seen even after 10 days in comparison with other Beta agonists (Beta-3 not specific) (Granneman 1992; Puy-Portillo et al. 1996). Lipolysis and cAMP response to BRL-37344 is described to be stable even for different kinds of adipocytes from Wistar rat, lean Zucker ( $\mathrm{Fa} /$ ?) rats, obese Zucker (fa/fa) rats and human fat. In comparison, the response to isoprenaline is not similar in these different cell types (Hollenga et al. 1991). Moreover, BRL-37344 is selectively activating cAMP-PKA pathway without concomitant ERK-MAPK activation. This feature is specific for this compound in contrast to other Beta-3 agonists (Gerhardt et al. 1999).

\section{Quantitative RT-PCR of iNOS}

Isolation of total mRNA was performed immediately after cultivation via RNAase lipid tissue mini kit according to the manufacturer's recommendation (Qiagen, Czech Republic). Quantitative real-time polymerase chain reaction (PCR) was performed using TaqMan Universal PCR Master mix (kit No. 4304437) and TaqMan Gene Expression Assays $\left(\mathrm{NOS}_{2}\right.$ kit No.: Rn00561646_m1 and beta 2 microglobulin (B2m) kit No.: Rn00560865_m1) obtained from Applied Biosystems (Foster City, CA, USA).

Relative quantification of gene expression - evaluation by real-time PCR-RNA integrity was determined by gel electrophoresis in $2 \%$ agarose gel stained with ethidium bromide. The total RNA concentration was estimated with fluorescence detection using an ultra sensitive RiboGreen RNA fluorescent nucleic acid reagent (kit No.R11490, Invitrogen) according to the manufacturer's instructions. RNA was stored in aliquots at $-80^{\circ} \mathrm{C}$ until use. cDNA was synthesized using $1.0 \mu \mathrm{g}$ of total RNA by help of RevertAidTM First Strand cDNA Synthesis (MBI Fermentas, Vilnius, Lithuania) with random hexamer primers according to the manufacturer's instructions. Expression of $\mathrm{NOS}_{2}$ and $B 2 m$ genes was estimated using RotorGene 6000 machine
(Corbett Research, Sydney, Australia). The real-time PCR reaction mixtures contained $10 \mu \mathrm{l}$ of $2 \mathrm{x}$ TaqMan Universal PCR Master Mix, $1.0 \mu \mathrm{l}$ of specific TaqMan probe (final concentration $250 \mathrm{nM}$, labeled with 6-FAM at the $5^{\prime}$-end and with non-fluorescent quencher at the 3 '-end, all Applied Biosystems), and primers for either B2m or $\mathrm{NOS}_{2}$ amplification (final concentration of $900 \mathrm{nM}$ each), $5 \mu \mathrm{l}$ of 4-times diluted cDNA template and water to a final volume of $20 \mu \mathrm{l}$. Cycling parameters were initial denaturation at $95^{\circ} \mathrm{C}$ for $15 \mathrm{~min}$, followed by 50 cycles consisting of denaturation at $95^{\circ} \mathrm{C}$ for $15 \mathrm{~s}$ and annealing/extension at $60^{\circ} \mathrm{C}$ for $60 \mathrm{~s}$. Fluorescence was acquired after each extension step. The non-template control contained water instead of cDNA. Levels of the gene transcripts were quantified from triplicates. B2m was used as an endogenous control. The $\mathrm{NOS}_{2}$ gene expression was evaluated by comparative quantification assuming that it equals to $2^{-\Delta \Delta \mathrm{ct}}$ where $\Delta \Delta \mathrm{ct}=$ $\Delta c t$ (sample of interest) $-\Delta c t$ (calibrator). $\Delta c t=c t$ (target gene, i.e. $\mathrm{NOS}_{2}$ ) - ct (endogenous control, i.e. $\mathrm{B} 2 \mathrm{~m}$ ) where ct represents threshold cycle at which the fluorescence rises appreciably above the background fluorescence. mRNA from untreated adipocytes of experimental rats served as the calibrator (its value was assumed to equal 1).

\section{Statistical analysis}

All experiments were performed at a minimum three times in triplicates (means of at least 9 values) with blind samples as the media background.

The statistical significance of difference of mean scores was determined using the paired (for comparison of nitrate+nitrite $v s$. nitrite levels) or unpaired two-tailed Student's $t$-test or one-way ANOVA with post hoc TukeyKramer multiple comparison test. The time-dependence examination experiments were performed separately for each time point, thus the time differences were compared using one-way ANOVA with post hoc Bonferroni pairwise comparison test, which compare data of longer time intervals with appropriate data of the shortest time interval in one experimental group. Results showing $p$ values less than 0.05 were considered statistically significant.

\section{Results}

Lipolysis in visceral adipocytes is mainly modulated by adrenergic pathway beside ANP pathway. In our experiments adipocytes were incubated in 24 hours with Beta- 3 agonist BRL-37344, PPARgamma agonist troglitazone, PPARgamma antagonist SR-202 and combination of the three treatments (see Table 1). Figure 1 demonstrates that the lipolysis was not significantly modulated by PPARagonist/antagonist in first 24 hours of primary isolated rat visceral adipocytes which 
suggests that direct effect of these treatments on lipolytic activity would not be significant. As expected, the Beta-3 agonist activation of lipolysis reached to $150 \%$ of control level. In contrast to the Beta- 3 triggered lipolysis was significantly down regulated by addition of troglitazone or SR-202 as seen in Figure 1. The observation that PPARgamma agonist and antagonist exhibited the same down regulation of Beta- 3 triggered lipolysis led us to the concept, that the activity of these two compounds may be mediated through a different mode than only the PPARgamma pathway. Published results show that AMPK could be the alternative way of action of thiazolidindiones and similar compounds (LeBrasseur et al. 2006).

Figure 2 depicts that the effect of troglitazone on Beta-3 triggered lipolysis is modulated by AMPK as AMPK selective blocker (compound C). Addition of compound C to troglitazone+Beta-3 agonist mixture increases Beta-3stimulated lipolysis to the level of Beta-3 alone level and in fact blocks the decrease caused by troglitazone.

As we found in the present results of an impact of PPARgamma agonists on lipolysis, we wonder if the same effect would appear in NO production since enhanced NO production during Beta-3 receptor activation in primary adipocytes was described in several reports (De Groot et al. 2003; Dessy et al. 2004; Canova et al. 2006).

The results of different treatment on NO production (Figure 3) demonstrate the same trend as shown with lipolysis in BRL-37344 (Beta-3 agonist) treatment, troglitazone (PPARgamma agonist) treatment and combination troglitazone and BRL-3734 treatments. The difference from lipolysis pattern can be seen in SR-202 addition to the mixture with troglitazone and to the mixture troglitazone and BRL-37344, where SR-202 exhibited additional increase of NO production in both cases, while in lipolysis combination of troglitazone and SR-202 showed no effect. In our experiments NO is increased after troglitazone/SR202 mixture but the effect of these compounds on Beta-3 agonist-triggered $\mathrm{NO}$ production is down-regulating. Moreover, the combination of PPARgamma agonist and antagonist should attenuate the effect and get back to basic control NO level. Instead the combination of PPARgamma agonist and antagonist show additive effect on NO production. The elevation of NO production after BRL$373344+$ troglitazone+SR-202 cannot be therefore explained as antagonist effect of SR-202 on troglitazone (otherwise SR-202 would block troglitazone effect on NO production when given in combination troglitazone+SR-202 without BRL-37344), rather this effect can be explained as additive effect of two independent pathways on NO production (similar results could be seen in our short-time $(30 \mathrm{~min})$ cultivation - data not shown).

The results of similar effect of PPARgamma agonist on Beta-3 pathway like in lipolysis and additive not opposite effect of PPARgamma agonist and antagonist mixture led us to investigate if this action is also mediated through AMPK pathway. As shown in Figure 4, AMPK blocker - compound $\mathrm{C}$ addition to troglitazone+Beta- 3 agonist mixture increases Beta-3-stimulated NO production to the level of only Beta-3 level and in fact attenuates the decrease caused by troglitazone. At least troglitazone effect on Beta-3-triggered NO production seems to be AMPK-dependent. These our results with NO could be explained by known AMPK decreased transcription of mRNA iNOS (Pilon et al. 2004). That is why iNOS quantitative RTPCR was performed. The results of mRNA-iNOS shown in Figure 5 demonstrate that NO production in visceral adipocytes depends mainly on increase iNOS transcription

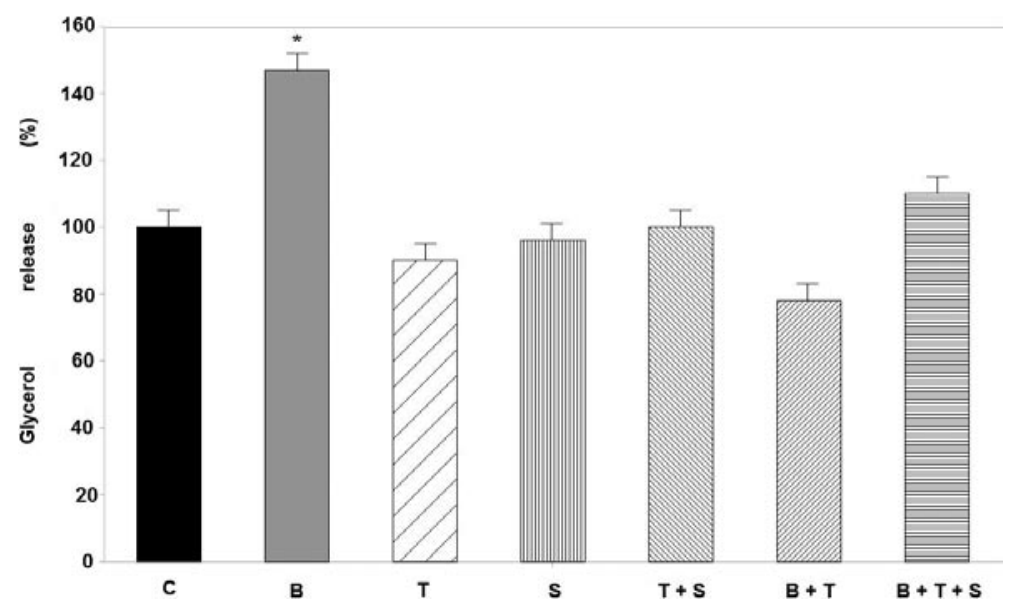

Figure 1. Effect of troglitazone, SR-202 and BRL-37344 and their combinations on lipolysis in isolated adipocytes expressed as free glycerol after 24 hour of cultivation. One-way ANOVA; ${ }^{\star} p<0.05 v s$. control and all other treatments. C, control; B, BRL-37344; T, troglitazone; S, SR-202. 


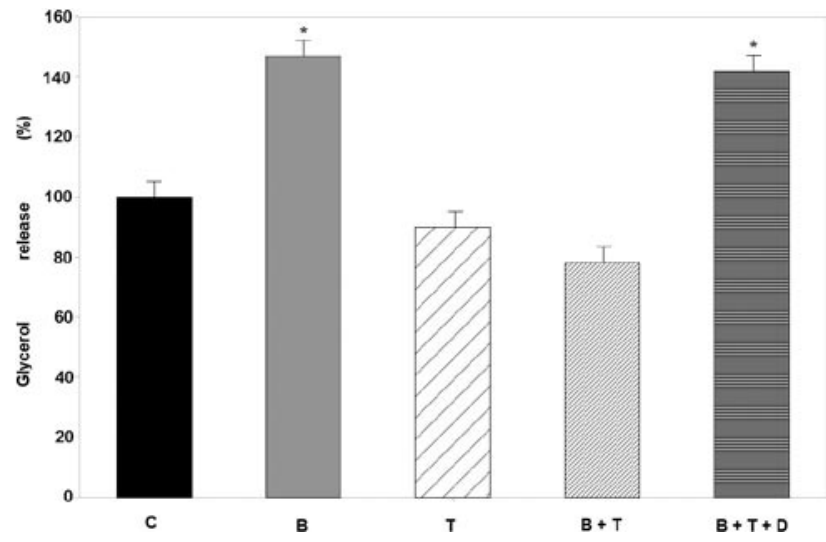

Figure 2. Effect of AMPK blocker - compound C on attenuation of BRL-37344-induced lipolysis with troglitazone. One-way ANOVA; ${ }^{\star} p<0.05 v$ s. control. D, compound C (other abbreviations see Fig. 1).

after Beta-3 agonist (400\% increase of iNOS mRNA level after BRL-37344). Mild enhancement of iNOS transcription can be seen in troglitazone treatment whereas combination of the Beta-3 agonist and troglitazone treatment completely blocks the iNOS mRNA transcription rate.

\section{Discussion}

The present data shed light on whether troglitazone (PPARgamma agonist) affect unstimulated lipolysis in 24 hours culture of visceral adipocytes. In our results the lipolysis was not significantly modulated by PPARgamma agonist or PPARgamma antagonist in first 24 hours of cultivation of vis- ceral adipocytes. Some published papers describe elevation of ATGL mRNA transcription (4-fold) after PPARgamma agonist in a period of 15 weeks in vivo treatment with glitazone (Shen et al. 2007) or ATGL and MGL mRNA increase after 12 hours of in vitro cultivation in adipose tissue (Festuccia et al. 2006). But ATGL and MGL type of lipase, however, were found not to have important impact on lipolysis in human fat tissue being less active in triglyceride lipolysis (ATGL 6-10 fold) than HSL (Mairal et al. 2006). One report demonstrates that rosiglitazone PPARgamma agonist produced 3-fold increase of HSL mRNA in 24 hours after treatment in hepatoma SMMC-7721 cell line and primary human fetal liver cells (CCC-L) but not in adipose tissue (Deng et al. 2006). We assume that direct effect of glitazones on constitutive lipolytic activity in adipocytes in short period of 24 hours could be small according to the present data.

On the other hand we followed the assumption that troglitazone affects BRL-37344 (Beta-3 agonist)-triggered lipolysis in 24 hours culture of visceral adipocytes. In contrast to troglitazone or SR-202 alone and in combination, the Beta-3-triggered lipolysis was significantly down-regulated by troglitazone alone or PPARgamma blocker SR-202 in our experiments. Although there is a report describing PPARgamma-dependent decrease of Beta-3 adrenergic receptor mRNA transcription in 24 hours cultivation of HIB-1B brown adipocytes (Bakopanos and Silva 2000), the observation that PPARgamma agonist and antagonist produced the same results (decrease of Beta-3-triggered lipolysis instead of opposing effect) led us to hypothesize, that the activity of these two compounds is possibly mediated through an alternative and not only PPARgamma pathway in white adipocytes.

According to the available literature, there are several alternative non-PPARgamma pathways activated by glita-

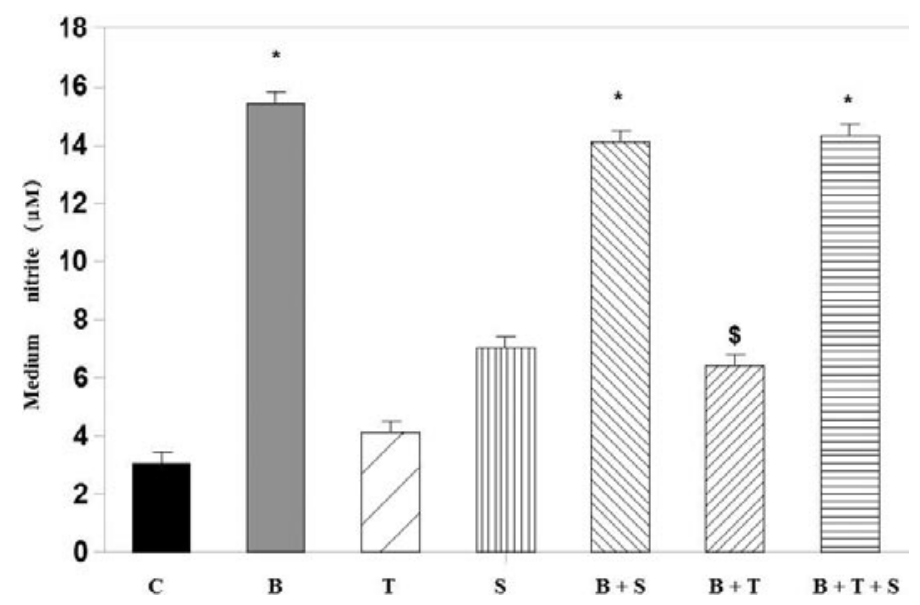

Figure 3. Effect of troglitazone, SR202 and BRL-37344 on NO production in isolated adipocytes expressed as $\mathrm{NO}_{2}{ }^{-}$. One-way ANOVA; ${ }^{*} p<0.05$ vs. control; ${ }^{\$} p<0.05$ vs. BRL-37344 (abbreviations see Fig. 1). 


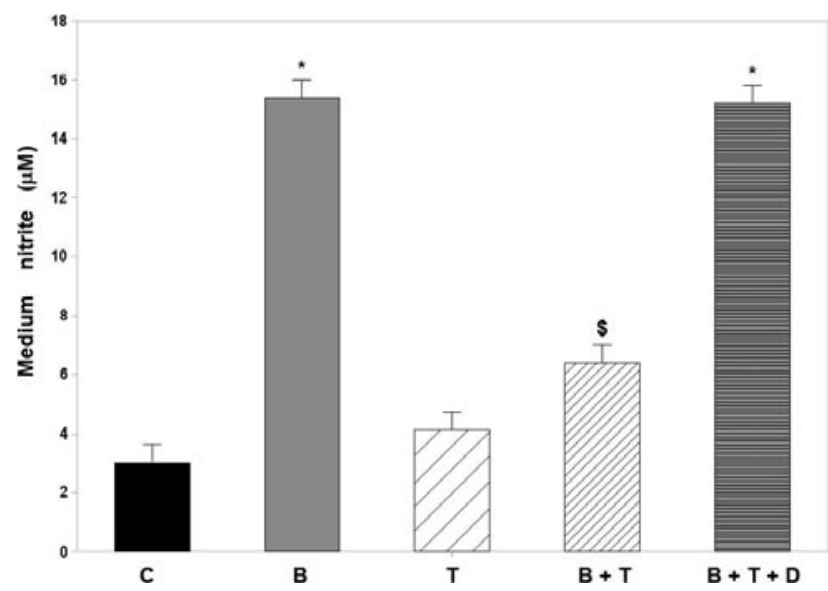

Figure 4. Effect of AMPK blocker - compound C on attenuation of BRL-37344-induced NO production with troglitazone. Oneway ANOVA; ${ }^{*} p<0.05 v$ s. troglitazone; ${ }^{\$} p<0.05$ vs. BRL-37344 (abbreviations see Fig. 2).

zones: AMPK (LeBrasseur et al. 2006), MAPK (Gardner et al. 2005), NFkB (Kurebayashi et al. 2005), PKC (Bahr et al. 1996) and others (Feinstein et al. 2005). That is why we used compound C - selective AMPK blocker into the present experiments. Since AMPK blocker added to medium attenuated the effect of glitazone/PPARgamma antagonist in our experiments, the AMPK pathway could be the possible explanation. There are reports suggesting AMPK pathway as antilipolytic effect for glitazone, e.g. AICAR (known as AMPK direct activator) treatment inhibited lipolysis both in 3T3-L1 adipocytes and visceral adipocytes (Sullivan et al. 1994; Daval et al. 2005). Also the expression increase

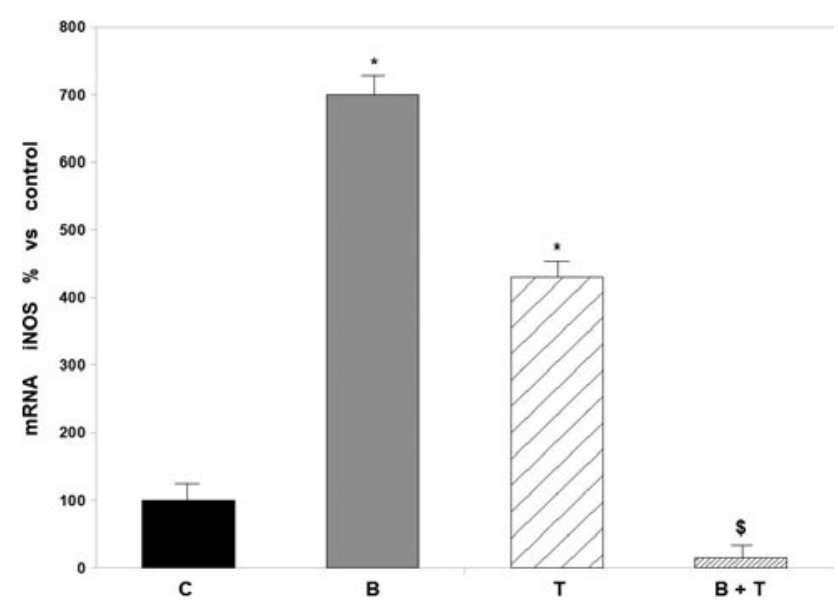

Figure 5. Quantitative RT-PCR rat iNOS after 24 hours. One-way ANOVA; ${ }^{*} p<0.05 v$ s. control; ${ }^{\$} p<0.05 v s$. BRL-37344 (abbreviations see Fig. 1). of gene encoding a constitutively active form of AMPK/ dominant negative form of AMPK in a1-AMPK subunit knock-out mice (the predominant subunit expressed in white adipocytes) had blocking effect on isoprenaline-mediated lipolysis (Yin et al. 2003). The main proposed mechanism of lipolysis regulation is believed to be regulatory phosphorylation of HSL. The supposed mechanisms of AMPK blockade of HSL is through phosphorylation in different site (site 2; Ser-565-constitutional site) than PKA activating phosphorylation site (site 1; Ser-563-regulatory site). After phosphorylation of HSL by PKA, activity of HSL increase by $61 \%$, while after AMPK phosphorylation of HSL the ability of PKA site 1 phosphorylation decreases with at least 20-30\% of lipolytic activity of HSL (Garton et al. 1989).

The impact of troglitazone on NO production is noteworthy. Troglitazone treatment exhibited an increase of NO production (Figs. 3, 4) and iNOS transcription (Fig. 5) in our experiments. This increase is even higher by addition of selective PPARgamma antagonist resulting in additive rather than opposite effect. These results also support the idea of nonPPARgamma effect of iNOS transcription and concomitant NO production. According to the available reports the PPARgamma agonists down regulate iNOS transcription (Li et al. 2000) in contrary to our experiments and SR-202 PPARgamma antagonist should block and not enhance the troglitazone effect. However, there are several pathways however activating iNOS transcription via PKA, NFkB, JAK/STAT, p38 MAPK and others (Kleinert et al. 2003). As troglitazone and other similar compounds are known to activate these pathways we can assume that iNOS transcription increase after troglitazone, SR-202 or their combination may be explained in this way.

Troglitazone has impact on NO production triggered by Beta-3 agonist and the profile of this effect is the same as in lipolysis. Beta-3-triggered iNOS transcription shows the opposite effect to that with troglitazone alone treatment. Troglitazone exhibited decreasing effect on iNOS transcription triggered by BRL-37344 (Figs. 4 and 5) which moreover seems to be AMPK dependent (Fig. 4). There are published data, that AMPK can decrease iNOS mRNA transcription triggered by LPS by $80-90 \%$ (Pilon et al. 2004). Although the exact mechanism is not clear so far, there are several crossroads of AMPK pathway and CAMP-PKA-pathway that can explain our result in the dramatic decrease of $\mathrm{NO}$ after Beta-3 agonist and PPARgamma agonist combinations. AMPK and PKA phosphorylate the identical site of cyclic AMP response element binding protein (CREB1) and therefore they can be competing at the same phosphorylation site (Thomson et al. 2008). AMPK is able inactivate p300 protein by phosphorylation of its Ser-89 site with concomitant reduction of its affinity for multiple nuclear receptors and interfere PKA activation of $\mathrm{p} 300$ protein (Leff 2003). Protein p300, after some authors, is crucial for iNOS 
mRNA transcription initiation (Deng et al. 2003; Granja et al. 2006). PKA can activate AMPK by phosphorylation enhancing the above mentioned effect in positive feedback. This could finally explain the effect of the dramatic decrease of iNOS mRNA transcription after Beta-3 and PPARgamma agonists' mixture treatments.

In our experiments we tried to elucidate possible interaction of PPARgamma and Beta-3 agonist in 24 hours of cultivation of visceral rat adipocytes. These interactions were proved mainly in PPARgamma blockade of Beta-3 agonist-induced lipolysis and NO production (together with iNOS transcription). We have shown in our results that both PPARgamma agonist and antagonist produced the same results supporting the theory, that the blockade is indeed nonPPARgamma-dependent. We found, moreover, that the effect is AMPK-dependent as AMPK blocker (compound C) attenuated both effect of PPARgamma agonist and antagonist on Beta-3-triggered lipolysis and NO production.

Acknowledgements. The authors would like to thank Eva Prchlíková, Libuše Šlehobrová and Alena Hloušková for their skilful technical assistance. This study was supported by grant GAČR 305/07/006, VZ MSM 021620807 and GAČR 305/97/0061.

\section{References}

Alderton W. K., Cooper C. E., Knowles R. G. (2001): Nitric oxide synthases: structure, function and inhibition. Biochem. J. 357, 593-615 doi:10.1042/0264-6021:3570593

Arner P. (2005): Human fat cell lipolysis: biochemistry, regulation and clinical role. Best Pract Res Clin. Endocrinol. Metab. 19, 471-482 doi:10.1016/j.beem.2005.07.004

Bahr M., Spelleken M., Bock M., von Holtey M., Kiehn R., Eckel J. (1996): Acute and chronic effects of troglitazone (CS-045) on isolated rat ventricular cardio- myocytes. Diabetologia 39, 766-774 doi:10.1007/s001250050509

Bakopanos E., Silva J. E. (2000): Thiazolidinediones inhibit the expression of beta3-adrenergic receptors at a transcriptional level. Diabetes 49, 2108-2115 doi:10.2337/diabetes.49.12.2108

Canová N. K., Lincová D., Kmoničková E., Kameníková L., Farghali H. (2006): Nitric oxide production from rat adipocytes is modulated by beta-3-adrenergic receptor agonists and is involved in a cyclic AMP-dependent lipolysis in adipocytes. Nitric Oxide 14, 200-211 doi:10.1016/j.niox.2005.06.006

Carpene C., Galitzky J., Collon P., Esclapez F., Dauzats M., Lafontan M. (1993): Desensitization of beta-1 and beta-2, but not beta-3, adrenoceptor-mediated lipolytic responses of adipocytes after long-term norepinephrine infusion. J. Pharmacol. Exp. Ther. 265, 237-247
Daval M., Diot-Dupuy F., Bazin R., Hainault I., Viollet B., Vaulont S., Hajduch E., Ferre P., Foufelle F. (2005): Anti-lipolytic action of AMP-activated protein kinase in rodent adipocytes. J. Biol. Chem. 280, 25250-25257 doi:10.1074/jbc.M414222200

De Groot A. A., Mathy M. J., Van Zwieten P. A., Peters S. L. (2003): Involvement of the beta-3 adrenoceptor in nebivolol-induced vasorelaxation in the rat aorta. J. Cardiovasc. Pharmacol. 42, 232-236

doi:10.1097/00005344-200308000-00012

Deng T., Shan S., Li P. P., Shen Z. F., Lu X. P., Cheng J., Ning Z.Q. (2006): Peroxisome Proliferator-Activated Receptor-gamma transcriptionally up-regulates hormone-sensitive lipase via the involvement of specificity protein-1. Endocrinology 147, 875-884

doi:10.1210/en.2005-0623

Deng W. G., Wu K. K. (2003): Regulation of inducible nitric oxide synthase expression by p300 and p50 acetylation. J. Immunol. 171, 6581-6588

Dessy C., Moniotte S., Ghisdal P., Havaux X., Noirhomme P., Balligand J. L. (2004): Endothelial beta-3-adrenoceptors mediate vasorelaxation of human coronary microarteries through nitric oxide and endothelium-dependent hyperpolarization. Circulation 110, 948-954 doi:10.1161/01.CIR.0000139331.85766.AF

Eberhardt W., Pluss C., Hummel R., Pfeilschifter J. (1998): Molecular mechanisms of inducible nitric oxide synthase gene expression by il-1b and cAMP in rat mesangial cells. J. Immunol. 160, 4961-4969

Elizalde M., Ryden M., van Harmelen V., Eneroth P., Gyllenhammar H., Holm C., Ramel S., Ölund A., Arner P., Andersson K. (2000): Expression of nitric oxide synthases in subcutaneous adipose tissue of nonobese and obese humus. J. Lipid Res. 41, 1244-1251

Feinstein D. L., Spagnolo A., Akar C., Weinberg G., Murphy P., Gavrilyuk V., Dello Russo C. (2005): Receptor-independent actions of PPAR thiazolidinedione agonists: Is mitochondrial function the key? Biochem. Pharmacol. 70, 177-188 doi:10.1016/j.bcp.2005.03.033

Festuccia W. T., Laplante M., Berthiaume M., Gélinas Y., Deshaies Y. (2006): PPARgamma agonism increases rat adipose tissue lipolysis, expression of glyceride lipases, and the response of lipolysis to hormonal control. Diabetologia 49, 2427-2436 doi:10.1007/s00125-006-0336-y

Fryer L. G., Hajduch E., Rencurel F., Salt I. P., Hundal H. S., Hardie D. G., Carling D. (2000): Activation of glucose transport by AMP-activated protein kinase via stimulation of nitric oxide synthase. Diabetes 49, 1978-1985 doi:10.2337/diabetes.49.12.1978

Gardner O. S., Dewar B. J., Graves L. M. (2005): Activation of mitogen-activated protein kinases by peroxisome-proliferator-activated receptor ligands: An example of nongenomic signaling. Mol. Pharmacol. 68, 933-941 doi:10.1124/mol.105.012260

Garton J., Campbell D. G., Carling D., Hardie D. G., Colbran R. J., Yeamans J. (1989): Phosphorylation of bovine hormone-sensitive lipase by the AMP-activated protein kinase. A possible antilipolytic mechanism. Eur. J. Biochem. 179, 249-254 doi:10.1111/j.1432-1033.1989.tb14548.x 
Gerhardt C. C., Gros J., Strosberg A. D., Issad T. (1999): Stimulation of the extracellular signal-regulated kinase $1 / 2$ pathway by human beta-3 adrenergic receptor: New pharmacological profile and mechanism of activation. Mol. Pharmacol. 55, 255-262

Granja A. G., Sabina P., Salas M. L., Fresno M., Revilla Y. (2006): Regulation of inducible nitric oxide synthase expression by viral A238L-mediated inhibition of p65/RelA acetylation and p300 transactivation. J. Virol. 10487-10496 doi:10.1128/JVI.00862-06

Granneman J. G. (1992): Effects of agonist exposure on the coupling of beta 1 and beta- 3 adrenergic receptors to adenylyl cyclase in isolated adipocytes. J. Pharmacol. Exp. Ther. 261, 638-642

Hollenga C., Brouwer F., Zaagsma J. (1991): Differences in functional cyclic AMP compartments mediating lipolysis by isoprenaline and BRL 37344 in four adipocyte types. Eur. J. Pharmacol. 200, 325-330 doi:10.1016/0014-2999(91)90590-M

Ji J. D., Cheon H. J., Jun J. B., Choi S. J., Kim Y. R., Lee Y. H., Kim T. H., Chae I. J., Song G. G., Yoo D. H., Kim S. Y., Sohn J. (2001): Effects of peroxisome proliferator-activated receptorgamma(PPAR-gamma) on the expression of inflammatory cytokines and apoptosis induction in rheumatoid synovial fibroblasts and monocytes. J. Autoimmun. 17, 215-221 doi:10.1006/jaut.2001.0542

Jobgen W. S., Fried S. K., Fu W. J., Meininger C. J., Wu G. (2006): Regulatory role for the arginine-nitric oxide pathway in metabolism of energy substrates. J. Nutr. Biochem. 17, 571-588 doi:10.1016/j.jnutbio.2005.12.001

Kleinert H., Schwarz P. M., Förstermann U. (2003): Regulation of the expression of inducible nitric oxide synthase. Biol. Chem. 384, 1343-1364 doi:10.1515/BC.2003.152

Kleinert H., Pautz A., Linker K., Schwarz P. M. (2004): Regulation of the expression of inducible nitric oxide synthase. Eur. J. Pharmacol. 500, 255-266 doi:10.1016/j.ejphar.2004.07.030

Knowles R. G., Moncada S. (1994): Nitric oxide synthases in mammals. Biochem. J. 298, 249-258

Kurebayashi S., Xua X., Ishii S., Shiraishi M., Kouhara H., Kasayamaa S. (2005): A novel thiazolidinedione MCC-555 down-regulates tumor necrosis factor-a-induced expression of vascular cell adhesion molecule-1 in vascular endothelial cells. Atherosclerosis 182, 71-77 doi:10.1016/j.atherosclerosis.2005.02.004

Lafontan M., Berlan M., Sengenes C., Moro C., Crampes F., Galitzky J. (2006): AMP- and cGMP-dependent control of lipolysis and lipid mobilization in humans: putative targets for fat cell management. In: Insights into Receptor Function and New Drug Development Targets. (Eds. M. Conn, C. Kordon and Y. Christen), pp. 53-77, Springer-Verlag, Berlin, Heidelberg doi:10.1007/3-540-34447-0_4

Lambert M., Neish A. C. (1950): Rapid method for estimation of glycerol in fermentation solutions. Can. J. Res. 28, 83-89

LeBrasseur N. K., Kelly M., Tsao T. S., Farmer S. R., Saha A. K., Ruderman N. B., Tomas E. (2006): Thiazolidinediones can rapidly activate AMP-activated protein kinase in mammalian tissues. Am. J. Physiol. Endocrinol. Metab. 291, E175-181 doi:10.1152/ajpendo.00453.2005

Leff T. (2003): AMP-activated protein kinase regulates gene expression by direct phosphorylation of nuclear proteins. Biochem. Soc. Trans. 31, 224-227 doi:10.1042/BST0310224

Li M., Pascual G., Glass C. K. (2000): Peroxisome proliferator-activated receptor gamma-dependent repression of the inducible nitric oxide synthase gene. Mol. Cell. Biol. 20, 4699-4707 doi:10.1128/MCB.20.13.4699-4707.2000

Mairal A., Langin D., Arner P., Hoffstedt. J. (2006): Human adipose triglyceride lipase (PNPLA2) is not regulated by obesity and exhibits low in vitro triglyceride hydrolase aktivity. Diabetologia 49, 1629-1636 doi:10.1007/s00125-006-0272-x

Martin G., Schoonjans K., Lefebvre A.M., Staels B., Auwerx J. (1997): Coordinate regulation of the expression of the fatty acid transport protein and acyl-CoA synthetase genes by PPARalfa and PPARgamma activators. J. Biol. Chem. 272, 28210-28217 doi:10.1074/jbc.272.45.28210

Nantel F., Bonin H., Emorine L. J., Zilberfarb V., Strosberg A. D., Bouvier M., Marullo S. (1993): The human Beta-3-adrenergic receptor is resistant to short term agonist-promoted desensitization. Mol. Pharmacol. 43, 548-555

Nathan D. M., Buse J. B., Davidson M. B., Ferrannini E., Holman R. R., Sherwin R., Zinman B. (2009): Medical management of hyperglycemia in type 2 Diabetes: a consensus algorithm for the initiation and adjustment of therapy: a consensus statement of the American Diabetes Association and the European Association for the Study of Diabetes. Diabetes Care 32, 193-203 doi: $10.2337 / \mathrm{dc} 08-9025$

Pilon G., Dallaire P., Marette A. (2004): Inhibition of Inducible nitric-oxide synthase by activators of AMP-activated protein kinase. J. Biol. Chem. 279, 20767-20774 doi:10.1074/jbc.M401390200

Portillo M. P., Del Barrio A. S., Garcia-Calonge M. A., Martinez J. A. (1996): Desenzitisation effect of in vivo treatment with metaproterenol on beta-1, beta- 2 and beta-3-adrenergic responsiveness in rat adipocytes. Life Sci. 58, 405-414 doi:10.1016/0024-3205(95)02305-4

Ranganathan G., Unal R., Pokrovskaya I., Yao-Borengasser A., Phanavanh B., Lecka-Czernik B., Rasouli N., Kern P. A. (2006): The lipogenic enzymes DGAT1, FAS, and LPL in adipose tissue: effects of obesity, insulin resistance, and TZD treatment. J. Lipid Res. 47, 2444-2450 doi:10.1194/jlr.M600248-JLR200

Rieusset J., Touri F., Michalik L., Escher P., Desvergne B., Niesor E., Wahli W. (2002): A new selective peroxisome proliferatoractivated receptor antagonist with antiobesity and antidiabetic activity. Mol. Endocrinol. 16, 2628-2644 doi:10.1210/me.2002-0036

Rodbell M. (1964): Metabolism of isolated fat cells. I. Effects of hormones on glucose metabolism and lipolysis. J. Biol. Chem. 239, 375-380

Shen W. J., Patel S., Yu Z., Jue D., Kraemer F. B. (2007): Effects of rosiglitazone and high fat diet on lipase/esterase expression in adipose tissue. Biochim. Biophys. Acta. 1771, 177-184

Schoonjans K., Peinado-Onsurbe J., Lefebvre A. M., Heyman R. A., Briggs M., Deeb S., Staels B., Auwerx J. (1996): PPARalfa 
and PPARgamma activators direct a distinct tissue-specific transcriptional response via a PPRE in the lipoprotein lipase gene. EMBO J. 15, 5336-5348

Sullivan J. E., Brocklehurst K. J, Marley A. E., Carey F., Carling D., Beri R. K. (1994): Inhibition of lipolysis and lipogenesis in isolated rat adipocytes with AICAR, a cell-permeable activator of AMP-activated protein kinase. FEBS Lett. 353, 33-36 doi:10.1016/0014-5793(94)01006-4

Thomson D. M., Herway S. T., Fillmore N., Kim H., Brown J. D., Barrow J. R., Winder W. W. (2008): AMP-activated protein kinase phosphorylates transcription factors of the CREB family. J. Appl. Physiol. 104, 429-438

doi:10.1152/japplphysiol.00900.2007
Vicario P. P., Candelore M. R., Schaeffer M. T., Kelly L., Thompson G. M., Brady E. J., Saperstein R., MacIntyre D. E., Tota L. M., Cascieri M. A. (1998): Desensitisation of Beta-3 -adrenergic receptor- stimulated adenylyl cyclase activity and lipolysis in rats. Life Sci. 62, 627-638 doi:10.1016/S0024-3205(97)01158-2

Yin W., Mu J., Birnbaum M. J. (2003): Role of AMP-activated protein kinase in cyclic AMP-dependent lipolysis in 3T3-L1 Adipocytes. J. Biol. Chem. 278, 43074-43080 doi:10.1074/jbc.M308484200

Revceived: May 25, 2010

Final version accepted: October 1, 2010 